\title{
The Reasons for Emergence of Born Global Firms ----Taking China as an Example
}

\author{
Shuyi Zhang \\ Economic \& Management College, Zhejiang Sci \& Tech University \\ School of Business Administration, Shanghai Finance University \\ 995 Shang chuan Road, Pudong \\ Shanghai 201209, China
}

Tel: 86-21-5021-8899Ｅ-mail: shyzhangvt@gmail.com

\begin{abstract}
With economic globalization and marketing integration, the born global firms, emerging as a new kind of enterprise, have arouses a wide rage of academic interest recently. Based on the previous research, this paper, taking the example of Zhejiang province, China, probes firstly into the main forming reasons of the born global including entrepreneurship, niche market, international management experience, and network, then points out the current problems of lacking innovative entrepreneurship, shorting of manager, Unreasonable industry structure, and finally, the paper puts forward some countermeasures from theoretical and practical approach for the Zhejiang born global firms.
\end{abstract}

Keywords: Born global, International management, Entrepreneur

\section{Background of research and literature review}

The roll of small and medium firms within the emerging market economy is well documented. We could find the increasingly active small firms in international market with estimates around 30 percent contribution to total Asia-Pacific Economic Cooperation. However, we could find that plenty of small businesses fail at their infancy or within a few years of inception. Some scholars attributed this to "resource poverty", lacking of financial capital or management skills. Within the past decades, a special kind of small firms, named as born global firms, has drawn academic attention. They entered the international market, sometimes bypassing to domestic market rapidly, overcoming partially the difficulty related resource and products. Born global firms are small ones that challenge the conventional theories of incremental or gradual internationalization because of the constraint of the "resource poverty" which limit the strategic option. A recent review of a decade of internationalization (Rialp-Criado, Rialp-Criado, Knight, 2002) concludes that the literature remains fragmented with a comprehensive explanation and casual model of phenomenon still lacking (Knight et al. 1996; Oviatt \& McDougall, 1997; Servais \& Rasmussen, 2000). In particular, little is known about the born global market strategies and process for understanding global market needs and developing new products.

Of course, constructing a unified theory goes beyond the limits of this study. Here we focus on the main factors in the rapid internationalization market performance of born global firms of Zhejiang province, China. How Zhejiang born global firms overcome their resource poverty has important implications not only for broadening the international business, but for developing theories of internationalization and international market performance also, and this is also the focus of this research.

Therefore, the research problem guiding this study is: what is the main factor about the internationalization processes of Zhejiang born global firms? And what are the existing issues about the Zhejiang born global firms and its countermeasures afterwards?

\section{The emergence of the Zhejiang born global firms}

The traditional international model U (Johanson and Vahlne, 1977, 1990) and model I (Bilkey and Tesar, 1977; Cavusgil, 1980; Reid, 1981) thought that the internationalization of the enterprise is usually a continuous process of evolution initiates from the domestic market into the international market along the path of geographical rotation and operating 
procedure. The essence of the model is the scale economy and similar demand preference, the former emphases the effect of the scale economy, while the latter thinks that the company should cumulate the experience and efficiency before exporting the products to the similar country, and stepping into the international trade. The above theory is the research finding of the giant company and its effect has been identified again and again by the development of the multinational company. But it is always the doubt whether it can be applied to the small and medium company. The international practice at home and abroad challenges the traditional cognition.

The challenge came firstly from European multinational company of science and technology. A report about 328 export oriented enterprises, which consists of the Sweden, Norway, Finland and Denmark, showed that most export enterprises began their international business right after their establishment, the offshore business is about 20 percent within one year, and could reach more than 50 percent after two years (Medson and Servais, 1997). They are organization of using the resources of many countries at the very beginning and sell the products in many countries to attain the competitive advantage. The responsiveness and the capability are the main factors of consideration (Oviatt and McDougall, 1994). Medson and Servais (1997) describe them as taking the international or global step after their initiation. Knight and Cavusgil (1996) further considered that the born global enterprises are those small tech-oriented companies with the employee less than 500, operating in the global market in the initial stage, using the cutting edge technology, meeting the demands of niche market with its high-tech products, the annual amount of sales less than $\$ 100$ millions, and the offshore business reach a quarter of the total sales within three years. Albeit most literature shows that the phenomenon of born global firms present to the emerging industries or high-tech sectors, and research demonstrated afterwards that born global firms can be find in so-called old and mature industry such as arts and crafts, and traditional industry in China (Yang, 2007).

A McKinsey report indicates that, compared with the traditional firms, the born global firms have the following characteristics: it views the world as the whole market not just the simple extension at the very beginning; its export more than one product within two years of establishment, and the export amount surpass the 25 percent of total sales; be established by the active entrepreneur, and has breaking process or technology; could develop a unique product originality, or new style of business; more value added in the product, usually in industrial products.

The private economy of Zhejiang province, China, focuses on the traditional industry of textile, leather, hardware, and is booming with the characteristics of cluster intergrowth. Relied on the unique entrepreneurship, Zhejiang private economy marches into the international market after the development of domestic market, now we could find Zhejiang entrepreneurs everywhere in European, America and other countries or regions. Although most company's globalization move along the path of domestic market first, international market second, some pioneer traditional companies who located in Wenzhou, Taizhou, Hangzhou, Ninbo, etc, go along the different direction, say, they pay the same attention to the domestic and international market, sometimes emphasis more on the international market, and finally bring out a new model of born global firms which is different with the European and American. Even though some Chinese scholars have been studying such an intriguing problem (Zhao, 2004; Yang, 2007), limited by the initial establish stage of export-oriented firms, the previous researches are in the beginning stage overall. That is why we interested in such a challenge topics.

\section{The motives of Zhejiang born global firms}

Since the born global having draw attention of academic community, the endeavor to explain such a phenomenon have never ceased. McDougall et al (1994) pointed out that traditional monopolistic advantage theory, product life cycle theory, internationalization stage theory and internalization theory, couldn't give born global firms a reasonable explanation. Basically, the explanation splits into two parts, one falls into the macro-aspect which attributes the born global firms to the change of the macro-environment, the other falls into micro-aspect which ascribes to the certain factors that relate to individual firms. For example, Medson and Servais (1997) attributed it to three aspects, such as the demand of the emerging market, the technology about the produce, transportation and communication, and more professional talent. Saarenketo (2002) proposed eight assumptions and attempted to verify the relationship between the market response and market concentration during their internationalization. Rialp-Criao, Rialp-Criao and Knight (2002) studied and reviewed the most representative 27 academic papers covering 15 kinds of journals, and came to the conclusion that the emerging market, technology development, global network and alliance, are key factors related with born global firms.

Mcdougall, Shane and Oviatt (1994) hoped to answer the formation of born global firms from three aspects. The first is about the subject of the internationalization, in their opinion, most of them are entrepreneurs who keep an ear to the ground of the outside information, they are either immigrant or have individual relationship with the overseas, or have experiences of internationalization; the second is the reason of born global, based on resource point of view, they explained why the born global happened in the inception of entrepreneur by overcoming the inherent inertia of refusing the change in the process of internationalization, and those born global entrepreneurs who circumventing the existing independent path at the very beginning, and are apt to get the resource globally; and the third is the type of business, 
born global firms control many important asset not by over investment but by multi-structure in the attainable scope of management.

As for the Zhejiang born global firms, Yang (2007) thought that the entrepreneurship, organizational learning and the enterprises network are the primary causes. Chen (2008) conducted an empirical study about the relationship between the entrepreneurship of the team and the company performance. Some researchers explored the impact on the internationalization performance of entrepreneurship and experience of born global firms with the case of Shenzhen, China. By studying the born global firms of the Yangze River Delta, Zhao (2004) demonstrated the importance of the global economy, niche market, technology improvement, and the implicit sensitivity.

Comparing with the foreign born global firms oriented high technology, most Zhejiang born global firms focus on the traditional industry because of their traditional inheritance. Generally speaking, the impetus of Zhejiang born global firms is attributed to the unique entrepreneurship, the network of businessman globally, the precise niche market, and technological development.

\subsection{The unique Zhejiang entrepreneurship}

Zhejiang is always in short of resource. There is a saying that the Zhejiang province is consists of 70 percent of mountain, 20 percent of land and 10 percent of water. With the economic reform and open-up, Zhejiang is famous for its private economy, no matter in it's inception and booming stage, we could find the unique entrepreneurship among Zhejiang born global firms, which is summarized as hardworking, pioneering innovation, the keen-to-change, the commitment to keep-faith, and the self-correcting inclusiveness. The innovation is the undercurrent keynote of the Zhejiang entrepreneurship. In fact, it is the innovation inheriting form old generation that turns the Zhejiang from resource of scarcity to richness, and become the pillar of Chinese national economy. Being good at catching market opportunity and starving for change, the asset of Zhejiang human resource, is the core competency of Zhejiang. As a matter of fact, you could find Zhejiang businessman anywhere no matter where you are going to. Made in Zhejiang, once the name of counterfeiting or inferior quality products, now turn out to be the name of competitive and high quality products.

It is the entrepreneur who is the carrier of the entrepreneurship. Zhejiang entrepreneurs are not only the businessman who allocates the resource, but also the important valuable asset themselves. They are tireless, aggressive, no taking things as they have, and not losing themselves for the achievements they have got (Luo, 2000). The large qualities of entrepreneurs who scattered in government administrative departments, state or private owned firms, are the talents for Zhejiang economic development. It is predisposition of entrepreneur that makes them not satisfying the status quo and advancing the organizational innovation so as to lead the small and medium born global firms.

Proposition 1: The innovation is the main factor of Zhejiang born global firms, the more innovative, the more inclined to born global firms.

\subsection{Accurate niche market}

Limited to the natural resource and size, most Zhejiang small and medium enterprises are difficult to compete with the large scale rivals, they usually choose the neglected market which is frail and potential as their target. For example, many enterprisers initiated their business from tiny-earning and become the profitable ones by means of accumulation such as "the king of button", "the king of stocking" which have a big market share afterwards.

The cluster economy and specialized zone, which derived from the niche market, are the prominent characteristics of Zhejiang economy. Because of the small size, the single enterprise is difficult to get cutting edge technology, high productive capacity. On the one hand, they usually unite to face the challenge by strategic alliance; on the other hand, they coordinate to form the specialized industrial zone by supply-demand chain, or the value chain so as to make more money for the customer as well as the company themselves.

In the strategy process of the born global firms, Zhejiang enterprises usually choose niche market at their infancy, and concentrate the natural and human resource on international market by the support of powerful cluster and specialization, and become the number one firstly, and then extend their market frontier, build the competitive barrier afterwards, and finally, obtain and strengthen the leadership in global market by stages. Usually, Zhejiang born global firms seldom go out beyond their control. Focusing on the specific industry, they persist in not stepping into unfamiliar industry, and not do what they have no assurance. Relying on the persistence and marching in niche market slowly and surely, they have obtained the profitable market gradually.

Proposition 2: The niche market is crucial for the Zhejiang born global firms. The more accurate market they focus on, the more market share and more leading position they will get.

\subsection{The international management background}

While competing with the rivals directly or indirectly, Zhejiang enterprises know well the international convention gradually, it benefits the global firms much, especially for those founders had working experience abroad or with 
international background. Feiyue Group, located in Taizhou, once a home shoe repairing factory, now turn out to be the large scale shoe maker who has more than 300 kinds of sewing products. At the very beginning, Feiyue sold its products in Latin America, Africa and many Asian countries and regions, and got much of the international experiences gradually, the company employed top foreign talents to conduct research and development, which help them to extend the global market within 20 years.

There are two basic models of Zhejiang born global firms, one is the split model, by which the global firm was derived from the parent company; and the other is established model which was founded by those who have been the top management team members and familiar with the international market very well. At the same time, the born global firms have obtained a plenty of managerial experiences in the process of international cooperation and competition. During the last decades, Zhejiang provincial government have done much either in introducing foreign talented person, or providing favorable policy to attract overseas to start their business in Zhejiang, and all these ensure the global firms booming in the international market now.

Proposition 3: The previous international background is very helpful for the born global firms, the more overseas experience the founder has, the more market share the firm extend in the future.

\subsection{The extensive enterprise network}

One of the most outstanding features of Zhejiang born global firms is the enterprise network based on interpersonal relationship by means of consanguinity, affinity, which was maintained and enforced by the inter-firm communication. This kind of interpersonal relationship network was established and demonstrated by cluster production and specialization. With more and more Zhejiang overseas' participation, the "Zhejiang village" or "Wenzhou village" could be seen around the world. And the relationship network in turn promotes their business. For example, after contacting with Wenzhou businessman who settled down in Hong Kong, Wenzhou lighter soon marched into the international market and got the most shares in light industry afterwards. Such an example could been found very often in such a industries, such as costume, shoes and hats, toys and other notions, in which the company has comparative advantages over the rivals.

In order to avoid the marketing risk, Zhejiang born global firms usually set up overseas industries zone led by one or more powerful firms, with the development of the zone, it attracts the other enterprises to settle down. The Yuemei Group, once set up a textile zone in Nigeria, and attracted other firms in upstream or downstream supply chain, and finally formed an industry chain from spinning, weaving, embroidering, knitting, to a complete set of costume. At present, Zhejiang has four state level overseas export-oriented economic and trade cooperation zones.

As for the network forming, the Zhejiang born global firms not only make use of existing network, but also develop new network so as to perfect the global network. For example, the Younger Group, a leading company focused on clothing, obtained 14 production bases located in the Sri Lanka, Philippine by merges and acquisitions, at the same time, it obtained more than 20 well-know brands, the top management team that has experience to supervise and design international brand.

To date, the investment model of Zhejiang born global firms have transformed from setting up offshore trading department to establishing overseas manufacturing factory, research and development center, and the establishment of offshore process is the new trend of foreign trade. So we have the following proposition.

Proposition 4: The Zhejiang born global firms is famous for its worldwide network. The more extensive network they have, the more resources they share.

\section{The problems and countermeasures for Zhejiang born global firms}

Zhejiang has something in common with the former Japan. As we all know, the Japan industry model has three features: to pursue the perfection at all costs, to improve and produce the innovation invented by other nations extensively, and to form the compact team. This model, emphasizing on the introversion without paying attention to the extraversion, focuses on the stable and gradual innovation of the manufacturing process instead of product breakthrough on the one hand; and also made it run into the tragedy of foam economy on the other hand. Generally speaking, Zhejiang born global firms are now short of the managerial innovation, extensive international market, and competitive strategic strategy fro some enterprises. Looking back the development of Zhejiang born global firms, we could find existing and potential problems as follow.

\subsection{Lacking plenty of innovative entrepreneurship}

The entrepreneurship is vital to the existence and development of born global firms. The personal endowment, say, risk preference, pioneering innovation, has a great influence on them. With the acceleration of global economy and integration of the international market, more and more global economic connection could be seen. Irrational factors don't work to allocate the resources inside or outside the enterprise, and hinder the growth of born global firms afterwards. Under such a circumstance, the Zhejiang entrepreneurship should go forward and fulfill the transition from 
the irrationality to rationality that needs more pioneer and innovative entrepreneurs. Therefore, the new generation should inherit their parents' entrepreneurship, comply with the main trends of global economy, and carry out three crucial transformations according to the market change, that is to say, to turn from the domestic market to international market, from developing countries to developed countries, and from the middle parts of manufacturing to the both ends of design and market in the value chain.

\subsection{Be in short of capable manager}

Born global firms need lots of higher qualified talent who not only familiar with the international convention, but have potential managerial capability also. Usually, one could find the family background in Zhejiang born global firms; even those with trillions of dollars of market share are still governed by the family member or their relatives. Because of their small size and insufficient international background at the very beginning, most Chinese traditional management characterized as man-ruled usually works. With the extensive management concerning about the strategic management and complex decision-making, more professionals are needed for international business. Thus the born global firms should employ more international managerial talents, and empower the executives to compete and cooperate in the global market.

\subsection{Unreasonable industry structure}

Most European born global firms focus on high-tech industry, such as information technology, telecommunication, electronics, and so on, while most Zhejiang born global firms derive from traditional labor-intensive industry. From viewpoint of international trend, high-tech industry, especially those integrating the modern telecommunication, information technology, have high value added and boom fast in the near future. Therefore, Zhejiang born global firms had better transform from traditional industry to modern technology, say, to transform from the traditional labor-intensive industry to the high-tech oriented industry.

One of the most likely ways to access to advanced technology is to invest the prosperous technology industry in developed countries, then to transmit and to spread to domestic enterprise so as to bring the "spillover effect" or "demonstration effect" into play. Usually, the technology attained by investment is comparatively more reliable than transforming or importing. According to the international convention, Zhejiang born global firms had better make good use of the international market, to build the overseas technology center with the reference of leading talents.

\section{The direction of further research}

As a new phenomenon, more and more born global firms have been found in Zhejiang, and other regions in China, and many other countries and regions. It's of theoretical and practical significance to study the academic frontier and promote the practice for small and medium enterprises. Based on the literature review, this paper probes into the impetus, the existing and potential problems of Zhejiang born global firms, and puts forth some suggestions. The future research could be done along the following two directions. The first is qualitative study of analyzing the pattern and its characteristics by the depth interview and questionnaire; and the other is qualitative analysis to study the internal relationship between the characteristic variables and performance of born global firms based on the cross-section or longitude data so as to advance the academic research.

\section{Acknowledgements}

I wish to thank Richard E. Wokutch, Pamplin Professor in the Department of Management at Virginia Tech, for inviting me to conduct a short time research as a visiting scholar in 2008. I am grateful for valuable suggestions from my colleagues of Zhejiang Sci \& Tech University and Shanghai Finance University as well as my graduate students.

\section{References}

Bell, J., McNaughton, R. \& Young, S. (2001). Born-again Global Firms: An Extension of the Born Global Phenomenon. Journal of International Management, 7: 173-189.

Bilkey, W. J. \& Tesar, G.. (1977). The Export Behaviour of Smaller-sized Wisconsin Manufacturing Firms. Journal of International Business Studies, 8 (1): 93-98.

Cavusgil, S.T. (1980). On the internationalization process of firms, European Research, 8(6): 273-281.

Chen, Zhongwei, \& Hao, Jailing. (2008). Empirical study on the relation between the entrepreneurship of team and performance of firms (in Chinese). Management Science, 21(1): 9-48.

Johanson, J. \& Vahlne, J.-E. (1977). The Internationalisation Process of the Firm: A Model of Knowledge Development and Increasing Foreign Markets Commitment. Journal of International Business Studies, 8 (1): 23-32.

Johanson, J. \& Vahlne, J.-E. (1990). The Mechanism of Internationalisatio. International Marketing Review, 7 (4): 11-24.

Knight, G. A., \& Cavusgil S. T. (1996). The born global firm: a challenge to traditional internationalization theory, In S. 
T., Cavusgil \& T. K. Madsen (eds.), Export internationalizing research - enrichment and challenges: 11-26, NY: JAI Press Inc.

Luo, Weidong. (2000). The entrepreneurship and the development of Zhejiang economy (in Chinese). Zhejiang Social Science, (2):13 15.

Madsen, T.K. \& Servais, P. (1997). The internationalization of born globals: an evolutionary process? International Business Review, 6(6): 561-583.

McDougall, P.P., Shane, S. \& Oviatt, B.M. (1994). Explaining the Formation of International New Ventures. Journal of Business Venturing, 9 (6): 469-487.

Oviatt, B. M. \& McDougall, P.P. (1994). Toward a Theory of International New Ventures. Journal of International Business Studies, 25 (1): 45-64.

Oviatt, B.M. \& McDougall, P.P. (1995). Global Start-ups: Entrepreneurs on a Worldwide Stage. Academy of Management Executive, 9 (2): 30-43.

Oviatt, B.M. \& McDougall, P.P. (1997). Challenges for Internationalisation Process Theory: The Case of International New Ventures. Management International Review, 37 Special Issue 1997/2: 85-99.

Reid, S.D. (1981). The Decision-maker and Export Entry and Expansion. Journal of International Business Studies, 12 (2): 101-112.

Rialp, A., Rialp, J., \& Knight, G.A. (2002). The Phenomenon of International New Ventures, Global Start-ups, and Born-Globals: What Do We Know After a Decade (1993-2002) of Exhaustive Scientific Inquiry?. Working paper, No. 2002/11.

Saarenketo, S. (2002). Born globals - Internationalization of small and medium-sized knowledge-intensive firms. Lappeenranta: Lappeenranta University of Technology.

Servais, P. \& Rasmussen, E.S. (2000). Different types of international new ventures, paper presented at the annual meeting of academy of international business (November), Phoenix, AZ., USA: 1-27.

Yang Zhong, Zhang Xia, Chen Yang and Liao Wenyan. (2007). Study on the sustainable driving force, the case study of the stage difference of cycle of born global firms (in Chinese). Management World, (6):122 136.

Yin, R. (1989). Case Study Research, Design and Methods. Beverly Hills, CA: Sage.

Zhao youzhen. (2004). The born global firm, concept, phenomenon, cause and enlightenments (in Chinese). International Business Study, (3): 65-69. 